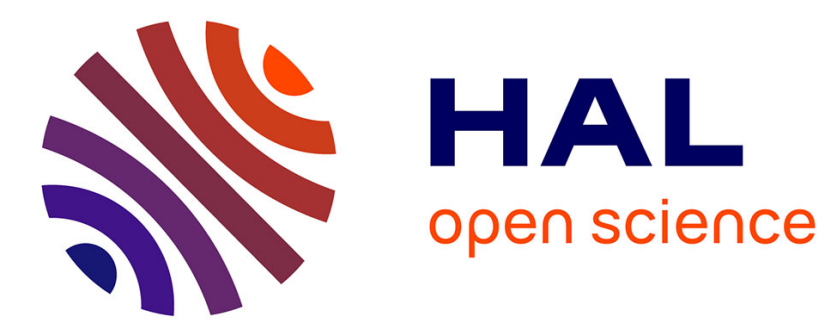

\title{
Chemoprevention of aberrant crypt foci in the colon of rats by dietary onion.
}

\author{
Sylviane Taché, Aélis Ladam, Denis E. Corpet
}

\section{To cite this version:}

Sylviane Taché, Aélis Ladam, Denis E. Corpet. Chemoprevention of aberrant crypt foci in the colon of rats by dietary onion.. European Journal of Cancer, 2007, 43 (2), pp.454-8. 10.1016/j.ejca.2006.09.022 . hal-00325672

\section{HAL Id: hal-00325672 \\ https://hal.science/hal-00325672}

Submitted on 29 Sep 2008

HAL is a multi-disciplinary open access archive for the deposit and dissemination of scientific research documents, whether they are published or not. The documents may come from teaching and research institutions in France or abroad, or from public or private research centers.
L'archive ouverte pluridisciplinaire HAL, est destinée au dépôt et à la diffusion de documents scientifiques de niveau recherche, publiés ou non, émanant des établissements d'enseignement et de recherche français ou étrangers, des laboratoires publics ou privés. 


\title{
Chemoprevention of aberrant crypt foci in the colon of rats by dietary onion
}

\author{
Sylviane Taché, Aélis Ladam, Denis E. Corpet
}

UMR Xénobiotiques, INRA, ENVT, 23 ch Capelles, F-31076 Toulouse, France

\section{ABSTRACT}

Onion intake might reduce the risk of colorectal cancer, according to epidemiology. However, Femia showed in 2003 that diets with $20 \%$ onion increase carcinogenesis in rats. We speculated this dose was too high. Prevention of initiation was thus tested in sixty rats given a $5 \%$ dried onion diet or AIN76 diet, and initiated $12 \mathrm{~d}$ later with azoxymethane (AOM, $1 \times 20 \mathrm{mg} / \mathrm{kg}$ i.p.), 2-amino-3-methylimidazo[4,5f]quinoline (IQ, 2x200mg/kg p.o.), or N-nitroso-Nmethylurea $(2 \times 50 \mathrm{mg} / \mathrm{g}$ p.o.). Prevention of promotion was tested in 38 rats given AOM, then randomised to: AIN76 diet; $5 \%$ onion diet; phytochemicals diet (supplemented with propyl-disulfide, quercetineglycosides and oligofructose); 1\% F68-pluronic diet (positive control). ACF were scored 30d (initiation) or $100 \mathrm{~d}$ (promotion) after carcinogen injection. The onion diet given during initiation reduced the number of AOM-induced ACF ( 60 vs. $86, p=0.03$ ), and the size of IQ-induced ACF (1.33 vs. 1.97, $\mathrm{p}=0.02$ ). Given post-initiation, the onion diet reduced the number of ACF (34 vs. 59, $p=0.008$ ) and of large ACF ( 6 vs. 15, $p=0.02$ ). Phytochemicals diet and pluronic diet reduced ACF growth similarly. Data show that $5 \%$ onion diet reduced carcinogenesis during initiation and promotion stages, and suggest this chemoprevention is due to known phytochemicals.

Abbreviations:: ACF, aberrant crypt foci; AOM, azoxymethane; IQ, 2-amino-3-methylimidazo[4,5f]quinoline; MNU, N-nitroso-N-methylurea

\section{Introduction}

Smart choices for better foods might prevent three colorectal cancers out of four (1). The main advice for a healthy diet is to eat more fruits and vegetables (2), but published intervention trials do not support this message yet $(3,4)$. One possible reason for the trials null effect is that all plants do not provide similar protection: volunteers may have increase their intake of non-protective vegetables. Allium vegetables including garlic and onion are amongst the most frequently cited as protective in case-control and cohort studies: Bianchini and Vainio (5) report eight case-control studies and three cohort studies dealing with garlic and/or onion and intestinal cancer: Out of those eleven studies, five studies report odd ratios $<0.4$ associated with onion or garlic intake, but only one reports an odd ratio $>1$.

Onions and garlic contain a wide variety of phytochemicals and of microconstituents such as trace elements, vitamins, fructans, flavonoids and sulphur compounds, which may have protective effects against cancer. Several studies show the protective potential of garlic components(6-8). Onion also contains alk(en)yl polysulphides and glycosides of flavonols, which can modulate hepatic drugmetabolizing enzymes in rats, and reduce the carcinogenicity of environmental chemicals $(6,9)$. We thus speculated that onion intake before and during initiation with a carcinogen may decrease carcinogenesis, if the agent needs metabolic activation.

In spite of these evidences that onion intake may protect against intestinal cancer, a recent study by Femia et al. suggests that onion intake may be detrimental (10). In their study, rats fed $20 \%$ onionbased diets, with low or high quercetin-glycoside content, surprisingly showed an increase in number, multiplicity, and "large" azoxymethane-induced aberrant crypt foci (ACF) compared to the control group. The ACF assay in which AOM-induced rats are fed with different experimental diets, has been widely used to test potentially chemopreventive agents, and the potency of most compounds to prevent ACF is correlated with the potency to prevent colon cancer (11).

This study was designed to test the three following hypotheses: (i) A realistic amount of onion intake may decrease ACF initiation by indirect carcinogens; (ii) A realistic amount of onion intake during the postinitiation phase, may decrease ACF growth; (iii) Postinitiation prevention by onion can be mimicked by a mixture of its known chemopreventive phytochemicals.

\section{Materials and methods}

\subsection{Animals, onions, and chemicals}

Ninety eight female F344 rats were obtained from Iffa Credo (Lyon, France) at 5 weeks of age. Rats were housed by pair in stainless steel wire drop-bottom cages. The light cycle consisted of $12 \mathrm{~h}$ each of light 
Table 1: Composition of experimental diets, given in $\mathrm{g}$ per $\mathrm{kg}$ of diet ${ }^{\mathrm{a}}$.

\begin{tabular}{|c|c|c|c|c|c|c|}
\hline Study & Initiatic & & & Post-in & iation & \\
\hline Diet & Control & Onion & Control & Onion & $\begin{array}{r}\text { Phyto- } \\
\text { chemicals }\end{array}$ & Pluronic \\
\hline Onion $^{b}$ & & 50 & & 50 & & \\
\hline Rafitlose $^{c}$ & & & & & 30 & \\
\hline Quercetin-glucosides $^{d}$ & & & & & 0.63 & \\
\hline Propyl-disulfide ${ }^{e}$ & & & & & 0.17 & \\
\hline Pluronic F68 $^{f}$ & & & & & & 10 \\
\hline Caseine & 200 & 200 & 200 & 200 & 200 & 200 \\
\hline Corn starch & 150 & 150 & 150 & 150 & 150 & 150 \\
\hline Sucrose & 500 & 500 & 540 & 500 & 510 & 540 \\
\hline Cellulose & 50 & 50 & 60 & 50 & 60 & 60 \\
\hline Corn oil & 50 & 50 & 50 & 50 & 50 & 50 \\
\hline Methionine & 3 & 3 & 3 & 3 & 3 & \\
\hline Mineral mix ${ }^{\mathrm{g}}$ & 35 & 35 & 35 & 35 & 35 & 35 \\
\hline Vitamin mix ${ }^{g}$ & 10 & 10 & 10 & 10 & 10 & 10 \\
\hline Choline bitartrate & 2 & 2 & 2 & 2 & 2 & 2 \\
\hline Total weight & 1000 & 1050 & 1050 & 1050 & 1050.8 & 1060 \\
\hline
\end{tabular}

a: Sum of dietary components was actually between 1000 and $1060 \mathrm{~g}$, as shown in Table 1 last line (data are easier to read than when all sums are adjusted to $1000 \mathrm{~g}$ ).

$\mathrm{b}$ : Onion dry powder was prepared as described in the Materials and Methods section. It contained $6 \% \mathrm{moisture,} \mathrm{X} \$ \mathrm{~g} / \mathrm{kg}$ fructans, $8.5 \mathrm{~g} / \mathrm{kg}$ flavonols, including quercetin 3,4'-diglucoside $4.2 \mathrm{~g}$ and quercetin 4'-glucoside $3.8 \mathrm{~g}$, dipropyl disulphide, methyl 1-propenyl trisulphide and propyl 1-propenyl trisulphide (not precisely quantified). The "Onion" diets thus contained $0.425 \mathrm{~g} / \mathrm{kg}$ quercetin glucosides.

c: Raftilose was provided by Orafti (Tienen, Belgium)

d: Quercetin-glycosides were purified from the onion powder, and contained $53 \%$ quercetin-monoglycoside, $42 \%$ quercetin-diglycoside, plus some free quercetin and isorhamnetin.

e: Propyl disulfide obtained from Aldrich (Lyon, France)

f: Pluronic F68 from Sigma Chemical Co. (St Louis, MO)

g: Mineral mix and vitamin mix according to the AIN-76 formula, provided like the other standard AIN-76 components by UAR (Villemoisson, France).

and dark. The animal room was maintained at $22 \pm$

$2^{\circ} \mathrm{C}$. Powdered AIN 76 diet (UAR, Villemoisson,

France) (12) and drinking water were provided ad libitum. Body weights, food and water intake, were monitored weekly throughout the study.

The onion powder was obtained from "Coop d'Or STL" (Auxonne, France). This powder was prepared from long-day yellow onions (Allium cepa) Auxor strain, Auxonne type, $15 \%$ dry matter, grown in the plain of Dijon (France). In a large-scale industrial plant, onions were washed and sliced before dehydrating through a conventional hot-air oven (temperature gradient from 85 to $45^{\circ} \mathrm{C}$ ) until the product retained less than $6 \%$ moisture. This onion powder contained $8.5 \mathrm{~g} / \mathrm{kg}$ flavonols, including quercetin 3,4'-diglucoside $4.2 \mathrm{~g}$ and quercetin 4'-glucoside $3.8 \mathrm{~g}(9)$. It also contained at least 15 different sulphur compounds: major ones were dipropyl disulphide, methyl 1-propenyl trisulphide and propyl 1-propenyl trisulphide, a pattern which is different from that of fresh onion (9). Quercetin-glycosides were purified from the abovecited onion powder by P. Goupy and M.J. Amiot (INRA, Avignon, France). Final product contained $53 \%$ quercetin-monoglycoside, and $42 \%$ quercetindiglycoside, plus some free quercetin and isorhamnetin.

Most chemicals were purchased from Sigma Chemical Co. (St Louis, MO), notably azoxymethane
(AOM), N-nitroso- $\mathrm{N}$-methylurea (MNU), and pluronic F68. 2-amino-3-methylimidazo[4,5-f]quinoline (IQ) came from ICN (Orsay, France), Raftilose from Orafti (Tienen, Belgium), propyl-disulfide from Aldrich (Lyon, France).

\subsection{Experimental procedure: onion effect on initiation by three carcinogens}

After seven days of acclimatization, sixty rats were randomly allocated to two groups of 30 rats. Control group was given the standard AIN 76 diet (UAR, Villemoisson, France). Experimental group was given the same diet supplemented with $5 \%$ onion powder for 14 or 17 days. Twelve days after starting the diets, all rats were given a carcinogen injection. Ten control rats and ten onion-fed rats were given one AOM i.p. injection (20 mg/kg body weight in saline). Ten controls and ten onion-fed rats were given two intra-gastric gavages with the heterocyclic amine IQ $(200 \mathrm{mg} / \mathrm{kg}$ on days 12 and 15, diluted in ethanol/saline 37:63). Similarly, ten controls and ten onion-fed rats were given two MNU gavages $(50 \mathrm{mg} / \mathrm{kg}$, on days 12 and 15 , diluted in citric acid 1\% pH 3). Experimental diets were maintained for two days after the last carcinogen injection. All rats were then given the control diet for 2628 days, and sacrificed by carbon dioxide asphyxiation thirty days after the first carcinogen injection. 
Table 2. Aberrant Crypt Foci (ACF) in the colon of rats fed an onion-based diet for two weeks before and during initiation by azoxymethane (AOM), 2-amino-3-methylimidazo[4,5-f]quinoline (IQ), or N-nitroso-N-methylurea (MNU).

\begin{tabular}{|c|c|c|c|c|}
\hline $\begin{array}{c}\text { Treatment: } \\
\text { Diet + Carcinogen }\end{array}$ & $\begin{array}{l}\text { Rats with ACF/ } \\
\text { Total No. of } \\
\text { Rats }\end{array}$ & ACF /Colon & $\begin{array}{l}\text { Large ACF } \\
\text { /Colon (>3 } \\
\text { crypts) }\end{array}$ & Crypts/ACF \\
\hline Control diet $+\mathrm{AOM}$ & $10 / 10$ & $86 \pm 28^{a}$ & $3.4 \pm 2.3$ & $1.71 \pm 0.12$ \\
\hline Onion diet + AOM & $10 / 10$ & $60 \pm 20^{b}$ & $2.5 \pm 2.0$ & $1.85 \pm 0.17$ \\
\hline Control diet + IQ & $5 / 9$ & $1.67 \pm 1.9$ & $0.11 \pm 0.33$ & $1.97 \pm 0.42$ \\
\hline Onion diet + IQ & $3 / 9$ & $0.67 \pm 1.1$ & 0.0 & $1.33 \pm 0.58^{b}$ \\
\hline Control diet + MNU & $10 / 10$ & $127 \pm 60$ & $2.3 \pm 1.8$ & $1.60 \pm 0.13$ \\
\hline Onion diet + MNU & $8 / 8$ & $120 \pm 55$ & $1.5 \pm 1.4$ & $1.66 \pm 0.15$ \\
\hline
\end{tabular}

\subsection{Experimental procedure: onion effect post- initiation by azoxymethane}

After seven days of acclimatization, thirty eight rats were given one AOM i.p. injection (20 mg/kg in saline). Seven days later, the rats were randomly allocated to four groups (10, 10, 10 and 8 rats). The control group was given the standard AIN 76 diet supplemented with $4 \%$ sucrose and $1 \%$ cellulose (to mimic carbohydrates from onion). The "onion" group was given the AIN 76 diet supplemented with $5 \%$ dried onion. The "phytochemicals" group was given the AIN 76 diet supplemented with three major onion phytochemicals (fructans, polyphenols and sulfides), at concentrations mimicking the onion content. This diet thus contained (g/kg diet): raftilose (30), quercetin-glycosides (0.630) and propyl-disulfide (0.166), to which $1 \%$ sucrose and $1 \%$ cellulose were added. A fourth group of 8 rats was given the same diet as the control group, supplemented with $1 \%$ pluronic F68, a very potent chemopreventive agent (13). One hundred days after the AOM injection all rats were sacrificed by carbon dioxide asphyxiation (experimental diets were thus given for 93 days).

\subsection{ACF scoring}

The colons were evaluated for ACF by Bird's procedure (14). They were excised and flushed with Kreb's Ringer solution, then opened longitudinally and fixed flat between coded filter papers in $10 \%$ buffered formalin. The colons were stained with methylene blue $(0.05 \%)$ for $6 \mathrm{~min}$, and then the mucosal side was observed at $40 \times$ magnification. ACF were distinguished from surrounding noninvolved crypts by their slit-like opening, increased staining, size and pericryptal zone. ACF size may relate more closely to the tumor end-point than ACF number. Thus, multiplicity (no. of crypts per ACF) was recorded for each ACF in each colon. All colons were scored blindly by a single observer. Large ACF were arbitrarily defined as containing 4 crypts or more ( $>3$ crypts/ACF), so that all rats in the postinitiation study would bear at least one large ACF. Data tables report mean number of ACF (and of large $\mathrm{ACF})$ per rat, and mean number of crypts per ACF.

\subsection{Statistical analysis}

Statistical analysis of post-initiation data set was done first by a one-way ANOVA. Pairwise comparisons were done using Student's t-test or Welch's t-test. P values less than 0.05 were considered significant.

\section{Results}

\subsection{Onion effect on initiation by three carcinogens}

The onion diet did not change the final body weight of rats, compared with control diet. At the end of the experiment, rats given IQ gavages were significantly heavier than rats given AOM or MNU (176 $\pm 7 \mathrm{~g}$ vs. $164 \pm 7 \mathrm{~g}$ or $160 \pm 7 \mathrm{~g}$, respectively, $\mathrm{p}<0.001$ ). Following MNU gavages, rats lost some weight: they lost $10 \mathrm{~g}$ between day 12 and 19. Two IQ and two MNU injected rats had to be euthanized before scheduled date because they were anemic and prostrated (three of them given the onion diet).

The effect of onion diet given before and during AOM, IQ or MNU injections, on number and multiplicity of colonic ACF is shown in Table 2. Onion-fed rats had fewer ACF, and fewer large ACF, than control rats, but chemoprevention was significant only against AOMinduced ACF. As already known, IQ gavages induced a small number of ACF compared to AOM and MNU: 
Table 3. Aberrant Crypt Foci (ACF) in the colon of rats given an azoxymethane injection, then fed for $93 \mathrm{~d}$ an AIN76 diet containing 5\% dried onion, a phytochemicals mix, or $1 \%$ pluronic F68.

\begin{tabular}{|c|c|c|c|c|}
\hline $\begin{array}{l}\text { Treatment: } \\
\text { Carcinogen and Diet }\end{array}$ & $\begin{array}{l}\text { No. of } \\
\text { Rats }\end{array}$ & ACF /Colon & $\begin{array}{c}\text { Large ACF } \\
\text { /Colon (>3 } \\
\text { crypts) }\end{array}$ & Crypts/ACF \\
\hline AOM then Control diet & $9^{a}$ & $59 \pm 20^{b}$ & $15 \pm 9$ & $2.7 \pm 0.4$ \\
\hline AOM then Onion diet & 10 & $34 \pm 15^{\mathrm{c}}$ & $6 \pm 4^{d}$ & $2.4 \pm 0.3$ \\
\hline AOM then Phytoch. Diet ${ }^{\dagger}$ & 10 & $40 \pm 19^{e}$ & $7 \pm 5^{d}$ & $2.6 \pm 0.3$ \\
\hline $\mathrm{AOM}$ then Pluronic diet & 8 & $41 \pm 13^{e}$ & $4 \pm 2^{c}$ & $2.2 \pm 0.2^{c}$ \\
\hline \multicolumn{5}{|c|}{$\begin{array}{l}\text { a One colon was damaged and could not be scored properly } \\
\text { b Values of mean } \pm S D \text {. } \\
\text { c Significantly different from control diet by Student's or Welch's test }(P<0.01) \text {. } \\
\text { d Significantly different from control diet by Welch's test }(P<0.05) \text {. } \\
\text { e Marginally different from control diet by Student's t test }(P=0.052) \text {. } \\
\text { t Phytochemicals mix (g/kg diet): raftilose (30), quercetin-glycosides }(0.63) \text { and propyl-disulfide }(0.17)\end{array}$} \\
\hline
\end{tabular}

10 rats/18 had no detectable ACF. Consequently, although onion-fed rats had 2.5 times fewer ACF than controls, the reduction was not significant. However, the IQ-initiated ACF contained significantly fewer crypts in the colon of onion-fed rats than in control rats. Onion diet did not change the number or size of MNU-induced ACF.

\subsection{Onion effect post-initiation by azoxymethane}

Control rats had a slightly smaller body weight than treated rats at the end of the experiment (controls, $180 \pm 7 \mathrm{~g}$ vs. $187 \pm 11,191 \pm 8$ and $190 \pm 12 \mathrm{~g}$, onion, phytochemicals and pluronic treated rats, respectively; ANOVA $p=0.06$ ). The effect of onion, phytochemicals and pluronic diets given one week after AOM injection, on number and multiplicity of colonic ACF is shown in Table 3. Onion-fed rats had fewer ACF $(p=0.008)$, fewer large ACF $(p=0.02)$, and slightly less crypts per ACF $(p=0.07)$ than control rats. A diet containing three major onion phytochemicals also reduced significantly the number of ACF $(p=0.05)$ and of large ACF $(p=0.04)$. The magnitude of the chemopreventive effect of onion and phytochemicals was similar to the protection afforded by $1 \%$ pluronic. However, in contrast with onion-fed rats, pluronic-fed rats had smaller ACF than controls $(p=0.005)$.

\section{Discussion}

In this study dietary onion significantly inhibited chemically-induced ACF formation in the colon of female F344 rats. Chemoprevention was significant against $A O M$ - and IQ-induced ACF, when onion was given during the initiation phase of carcinogenesis. In contrast, no chemopreventive effect was observed at this stage against MNU-induced ACF. Because MNU is a direct-acting carcinogen, but $A O M$ and IQ need to be activated before reaching DNA, we think that onion effect was due to inhibition of activating enzymes, as suggested by Wargovich et al. (7).
Indeed, Teyssier et al. showed that the dried onion that was used in this study induces CYP $1 \mathrm{~A}$ and CYP $2 \mathrm{~B}$ activities in the liver, while decreasing CYP 2E1 activity. Dried onion also doubles UDPglucuronosyltransferase activity and slightly increases glutathione S-transferase activity (9). That onion-based diet could inhibit IQ-induced carcinogenesis seems particularly relevant, because fried meat that brings heterocyclic amine to consumers is often eaten with onions.

Chemoprevention was also significant against the formation and/or the growth of AOM-induced ACF, when onion was given during the post-initiation phase of carcinogenesis. Post-initiation chemoprevention cannot be explained by the inhibition of AOMmetabolizing enzymes, since onion diet started one week after AOM injection. We speculated that postinitiation effect of onion might be mimicked by a mixture of its known chemopreventive components. Indeed, rats given dried onion and rats given a mixture of fructan, flavonoid and sulphur compounds had similar numbers of large ACF. This does not prove, but strongly suggest, that these compounds alone can explain the onion chemopreventive effect. However, this study does not tell which agent is active post-initiation, or if the mixture is mandatory to decrease ACF formation.

It is surprising that Femia et al., using a protocol similar to this one, obtained very different results (10). In their study, onion-fed rats had twice more ACF and three times more "large ACF" than control rats. However, they included $20 \%$ dry onion in the diet, vs. $5 \%$ in this study. This very high onion dose was chosen to reach quercetin level previously shown to prevent carcinogenesis. Indeed, quercetin levels were similar in Femia's study and this one (0.6$0.7 \mathrm{~g} / \mathrm{kg}$ ). Diet containing more that $20 \%$ dried onion can be toxic, and induces haemolysis and anaemia in cattle and in dogs. To quote Femia et al.: "We cannot rule out the possibility that a lower onion supplementation may have had a beneficial 
effect"(10). Other differences between this protocol and Femia's one are low-fat diet vs. high-fat diet, single AOM injection vs. two AOM injections, female vs. male rats, and sacrifice 30 and $100 \mathrm{~d}$ after AOM vs. $49 \mathrm{~d}$ after AOM. We do not think, however, that these differences could account for the discrepancy between studies results. In contrast, we think that an agent may be beneficial at a low level, but "too much of a good thing" may be detrimental, as suspected also for beta-carotene and folic acid $(15,16)$.

How does the prevention efficacy of onion compare with other chemopreventive agents? To answer this question, we used the online Chemoprevention Database that reports all studies of agents with a significant chemopreventive effect $(11,17)$. Its May 2006 update contained 339 ACF studies (median efficacy, 1.9). In this study, onion-based diets reduced the number of ACF by $1.4,2.5$, and 1.7 (86/60 and 1.67/0.67, Table 2; 59/34, Table 3). These values correspond to the $88^{\text {th }}, 195^{\text {th }}$ and $300^{\text {th }}$ agent in the ranked list with the most potent agent on top. In addition, the onion effect here was similar to the effect of a sub-optimal dose of pluronic F68 (1\% instead 5\%). Onion thus appears to possess average chemoprevention potency. In addition, would it be possible for a human consumer to eat as much onion as was given these rats? Rats weighing $185 \mathrm{~g}$ were eating $0.5 \mathrm{~g} / \mathrm{d}$ of dried onion. Extrapolation of this intake on metabolic weight basis suggests that a 60 $\mathrm{kg}$ human volunteer should eat $30 \mathrm{~g}$ of dried onion per day. This is clearly a high intake, but a possible one.

In conclusion, this study shows that a $5 \%$ onionbased diet inhibited the chemical initiation of preneoplastic lesions in the colon of rats, and reduced their post-initiation growth. Provided the daily amount is not too high, onion may thus be a useful component of a cancer-preventive diet.

\section{Acknowledgements}

The authors thank Rémy Kahane (Coop d'Or - STL, Auxonne, France) for giving dried onion powder, and Pascale Goupy (INRA, Avignon, France), for analysing onion flavonoids and giving us purified quercetine-glucosides. This work was supported by a grant of the French Ministere de la Recherche (no. 98 P0470).

\section{References}

1. Cummings JH, Bingham SA. Fortnightly review - diet and the prevention of cancer. British Medical Journal 1998, 317, 1636-1640.

2. WCRF WCRF. Food, nutrition and the prevention of cancer: a global perspective. WCRF and American Institute for Cancer Research, Washington DC 1997, 1-.
3. Schatzkin A, Lanza E, Corle D, et al. Lack of effect of a low-fat, high-fiber diet on the recurrence of colorectal adenomas. New England Journal of Medicine 2000, 342, 1149-1155.

4. Beresford SA, Johnson KC, Ritenbaugh C, et al. Low-fat dietary pattern and risk of colorectal cancer: the Women's Health Initiative Randomized Controlled Dietary Modification Trial. Jama 2006, 295, 643-54.

5. Bianchini $F$, Vainio $H$. Allium vegetables and organosulfur compounds: do they help prevent cancer? Environmental Health Perspectives 2001, 109, 893-902.

6. Fukushima S, Takada N, Hori T, Wanibuchi $\mathrm{H}$. Cancer prevention by organosulfur compounds from garlic and onion. Journal of Cellular Biochemistry 1997, 100-105.

7. Wargovich MJ, Uda N, Woods C, Velasco M, Mckee K. Allium vegetables: their role in the prevention of cancer. Biochemical Society Transactions 1996, 24, 811-814.

8. Ross SA, Finley JW, Milner JA. Allyl sulfur compounds from garlic modulate aberrant crypt formation. J Nutr 2006, 136, 852S-854S.

9. Teyssier C, Amiot MJ, Mondy N, Auger J, Kahane $\mathrm{R}$, Siess $\mathrm{MH}$. Effect of onion consumption by rats on hepatic drug-metabolizing enzymes. Food and Chemical Toxicology 2001, 39, 981-987.

10. Femia AP, Caderni G, lanni M, et al. Effect of diets fortified with tomatoes or onions with variable quercetin-glycoside content on azoxymethaneinduced aberrant crypt foci in the colon of rats. Eur $J$ Nutr 2003, 42, 346-52.

11. Corpet DE, Tache S. Most effective colon cancer chemopreventive agents in rats: a systematic review of aberrant crypt foci and tumor data, ranked by potency. Nutrition and Cancer 2002, 43, 1-21.

12. American loN. Report of the American Institute of Nutrition Ad Hoc Committee on standards for nutritional studies. J Nutr 1977, 107, 1340-1348. 13. Parnaud G, Tache S, Peiffer G, Corpet DE. Pluronic F68 block polymer, a very potent suppressor of carcinogenesis in the colon of rats and mice. British Journal of Cancer 2001, 84, 90-93.

14. Bird RP. Observation and quantification of aberrant crypts in murine colon treated with a colon carcinogen: preliminary findings. Cancer Lett 1987, 37, 147-151.

15. Ulrich CM, Potter JD. Folate supplementation: too much of a good thing? Cancer Epidemiol Biomarkers Prev 2006, 15, 189-93.

16. Raju J, Swamy MV, Cooma I, et al. Low doses of beta-carotene and lutein inhibit AOMinduced rat colonic ACF formation but high doses augment ACF incidence. Int J Cancer 2005, 113, 798-802.

17. Corpet DE, Tache S, Pierre F. The Chemoprevention Database: Experimental colon cancer prevention studies in carcinogen induced rats, in Min mice, and in human volunteers.

http://www. inra.fr/reseau-nacre/scimemb/corpet/indexan.htm/2002-2006, May 2006. 